\title{
Dynamic triggering of high-frequency bursts by strong motions during the 2004 Parkfield earthquake sequence
}

\author{
Adam D. Fischer, ${ }^{1}$ Zhigang Peng, ${ }^{2}$ and Charles G. Sammis ${ }^{1}$ \\ Received 7 March 2008; revised 1 April 2008; accepted 4 April 2008; published 21 June 2008.
}

[1] High-pass filtering $(>20 \mathrm{~Hz})$ of acceleration records from the USGS Parkfield Dense Seismograph Array (UPSAR) reveals a series of bursts that occur only during strong shaking from the 2004 Mw6 Parkfield, California, earthquake and its immediate aftershocks. Because there is no correlation between these high frequency bursts observed at closely spaced stations, we hypothesize that they are associated with dynamically triggered events occurring within 20 meters of the stations in the highly fractured shallow crust. The triggering threshold was found to be $\sim 0.02 \mathrm{MPa}$, consistent with a previous estimate based on a similar analysis of high-frequency bursts observed in strong motion data from the 1999 Chi-Chi earthquake in Taiwan (Fischer et al., 2008). The consistent observation of high-frequency bursts at both Parkfield and Taiwan suggest that they may be a common phenomenon associated with strong motion in the very shallow crust. Citation: Fischer, A. D., Z. Peng, and C. G. Sammis (2008), Dynamic triggering of high-frequency bursts by strong motions during the 2004 Parkfield earthquake sequence, Geophys. Res. Lett., 35, L12305, doi:10.1029/2008GL033905.

\section{Introduction}

[2] The high-frequency content of seismic signals recorded by surface seismometers can be attributed to a number of processes. These include high-frequency radiation from the source region [e.g., Peng et al., 2006], scattering [e.g., Ebel, 1989; Wilson and Pavlis, 2000], reverberation in near-surface layers [Blakeslee and Malin, 1991], and dynamic triggering of local earthquakes and non-volcanic tremor during the passage of regional and teleseismic surface waves [e.g., Hill et al., 1993; Prejean et al., 2004; Hill and Prejean, 2007; Gomberg et al., 2008; Miyazawa and Brodsky, 2008].

[3] Many studies have shown that the top few hundred meters of the crust can produce and attenuate highfrequency waveforms [Hanks, 1982; Shearer and Orcutt, 1987; Cranswick, 1988; Ebel, 1989; Blakeslee and Malin, 1991; Vernon et al., 1991, 1998; Wilson and Pavlis, 2000]. This layer is extremely fractured and weathered, and is characterized by low shear wave velocity $(\sim 200-400 \mathrm{~m} / \mathrm{s})$ and a very high attenuation $(\mathrm{Q} \sim 1-10)$ [e.g., Aster and Shearer, 1991]. Other recent studies have found high-

\footnotetext{
${ }^{1}$ Department of Earth Sciences, University of Southern California, Los Angeles, California, USA.

${ }^{2}$ School of Earth and Atmospheric Sciences, Georgia Institute of Technology, Atlanta, Georgia, USA.
}

Copyright 2008 by the American Geophysical Union. 0094-8276/08/2008GL033905\$05.00 frequency spikes (or cusped waveforms) in the latter portions of the strong-motion seismograms from stations on soft soils for several large earthquakes [e.g., Holzer et al., 1989; Frankel et al., 2002; Bonilla et al., 2005]. Bonilla et al. [2005] suggested that the high frequency spikes in these acceleration records could be related to an increase of effective stress and strain hardening due to an increase of pore pressure in the granular material under large strains.

[4] Recently, band-pass filtered acceleration records of strong motion $P$ - and $S$-waves generated by the 1999 Mw7.6 Chi-Chi, Taiwan, earthquake were observed to contain high-frequency $(>20 \mathrm{~Hz})$ bursts at distances up to $170 \mathrm{~km}$ from the epicenter [Fischer et al., 2008]. These bursts differ from anything previously observed in that they are small, discrete higher-frequency packets superimposed on the much larger lower-frequency strong motion, and they are only apparent through either extreme magnification and detrending or high-pass filtering [Chen et al.. 2006; Fischer et al., 2008]. Fischer et al. [2008] suggested that they are local triggered events located in the highly damaged and weathered top few hundred meters of the crust, a hypothesis supported by their observation at large distances from the fault plane and a lack of correlation at neighboring stations. That work challenged the original interpretation by Chen et al. [2006], who argued that the sources of the bursts were located on the Chelungpu fault plane that ruptured during the Chi-Chi earthquake. By comparing the seismic signals at stations that recorded bursts with those that did not, Fischer et al. [2008] found a threshold stress for dynamic triggering by $\mathrm{S}$-waves to range from 0.03 to $0.05 \mathrm{MPa}$, depending on the signal-to-noise ratio (SNR) used to define the bursts.

[5] In this study we document similar high-frequency bursts observed by the USGS Parkfield Dense Seismograph Array (UPSAR) during the strong shaking from the 2004 Mw6 Parkfield earthquake (Figure 1) and its largest immediate aftershocks. Our primary goals are to document highfrequency bursts in a region other than Taiwan and to better constrain their locations and sizes using the closer station spacing at Parkfield.

\section{Observation of Bursts on the UPSAR Records During the 2004 Parkfield Earthquake}

[6] The Parkfield mainshock occurred at 17:15:14 UTC on 28 September 2004 with an epicenter $11 \mathrm{~km}$ southeast of Parkfield, California [Langbein et al., 2005], and was followed by numerous aftershocks. The UPSAR array is located about $10 \mathrm{~km} \mathrm{SE}$ of the Parkfield segment of the San Andreas Fault (SAF), and consists of 14 stations within an area of about $1 \mathrm{~km}^{2}$. Each station has a three-component weak-motion velocity transducer and a strong-motion accelerometer, which are recorded at 200 samples per second 


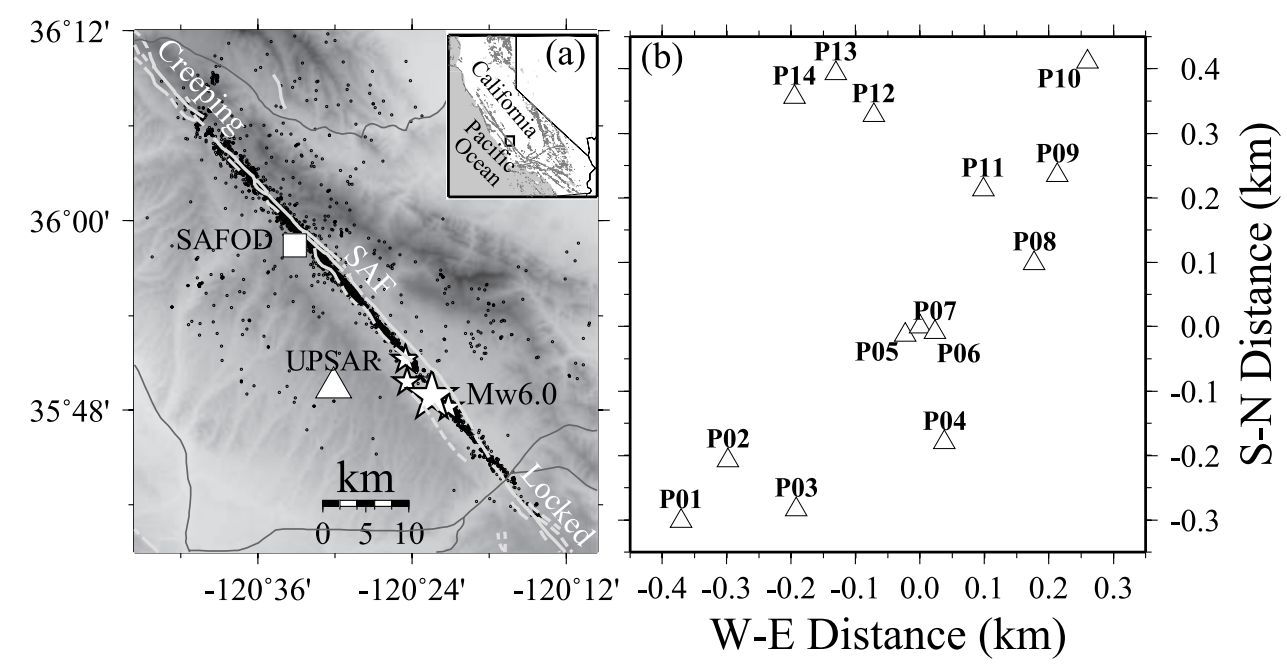

Figure 1. (a) Map view of San Andreas Fault near Parkfield, CA. The 2004 M6 Parkfield earthquake and large early aftershocks are indicated by stars and other aftershocks are shown as dots. The thick gray and light lines denote surface traces of SAF and nearby roads, respectively. The background is shaded topography with white being low and dark being high. The locations of the USGS Parkfield Dense Seismograph Array (UPSAR) and the SAFOD are denoted by the inverted triangle and square, respectively. The inset shows the study area on a map of California. (b) Small scale view of UPSAR stations. The distances are relative to station P06.

[Fletcher et al., 1992]. These recordings are ideal for searching for dynamically triggered high-frequency bursts during the strong shaking associated with the Parkfield earthquake sequence.

[7] We searched for bursts by applying a 4th order Butterworth high-pass filter with a cutoff frequency of $20 \mathrm{~Hz}$ to all the strong motion recordings from the 12 active stations during the first 900 seconds of the Parkfield earthquake sequence (Figure 2). We chose $20 \mathrm{~Hz}$ as a lower cutoff because seismic energy above this frequency attenuates very quickly and is less likely to be contaminated by radiation from the mainshock source region, and because this is the frequency range in which high-frequency bursts were observed in Taiwan [Chen et al., 2006; Fischer et al., 2008]. We observed high-frequency bursts on the filtered records from all three components of all 12 stations during the strong shaking from the Parkfield mainshock (Figures $2-3$ and $\mathrm{S}^{1}-\mathrm{S} 3$ ). The amplitudes and durations of these bursts are similar to those observed in Taiwan [Chen et al., 2006; Fischer et al., 2008]. Bursts were also observed during strong shaking associated with three largest immediate aftershocks $(M w \geq 4)$ at Parkfield, but not during the relatively quiet periods between these events.

[8] Although Peng et al. [2006] used a similar high-pass filtering technique to identify many early aftershocks in the source region that were not in the standard earthquake catalogs, it is evident from Figure 2 that the bursts observed here are different in that they are not clearly correlated at different stations in the array. Even the largest amplitude burst observed during the Parkfield mainshock cannot be clearly identified at any nearby station, although there are many small amplitude events at about the same time that might be correlated (see, for example, the large burst at station P10 in Figure 2 at $\sim 8$ s). This first-order

\footnotetext{
${ }^{1}$ Auxiliary materials are available in the HTML. doi:10.1029/ 2008GL033905.
}

observation suggests that the high-frequency bursts are most likely due to a phenomenon located very near each station.

\section{Burst Identification Algorithm}

[9] Our automated algorithm for identifying bursts generally follows that by Fischer et al. [2008] and is briefly described here. The accelerograms were first high-pass filtered at $20 \mathrm{~Hz}$ using a 4th order Butterworth filter. Bursts were identified using an algorithm that imposed an amplitude threshold based on the SNR. Local minima and maxima were found by differentiation and local extrema that exceeded the amplitude threshold were saved. If any two saved picks occurred within 0.2 seconds of each other, they were considered as a single event. We also required that a burst appear on all three components.

[10] This algorithm picked bursts that were obvious by visual inspection, but it also picked events that were not obvious or appeared as a relatively continuous "tremorlike" signal [e.g., Obara, 2002]. Most of these questionable picks were eliminated by increasing the SNR threshold and paying the penalty of reducing the total number of identified bursts. We found that a SNR of 50 gave the best agreement with visual inspection.

[11] We used this algorithm to search for bursts on the records from all 12 operating UPSAR stations during a 900 second interval that include the Parkfield mainshock and its early aftershocks. We found 648 high-frequency bursts using the $\mathrm{SNR}=10,136$ bursts using $\mathrm{SNR}=50$, and 44 bursts using $\mathrm{SNR}=100$.

\section{Triggering Threshold}

[12] If the high-frequency bursts originate in the shallow crust very near the stations and are dynamically triggered by strong ground motions [Fischer et al., 2008], then the triggering threshold can be estimated by calculating the 
(a)

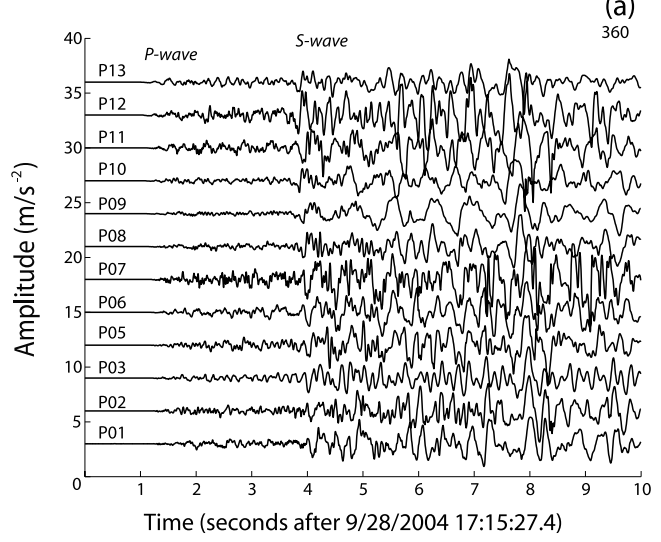

(b)

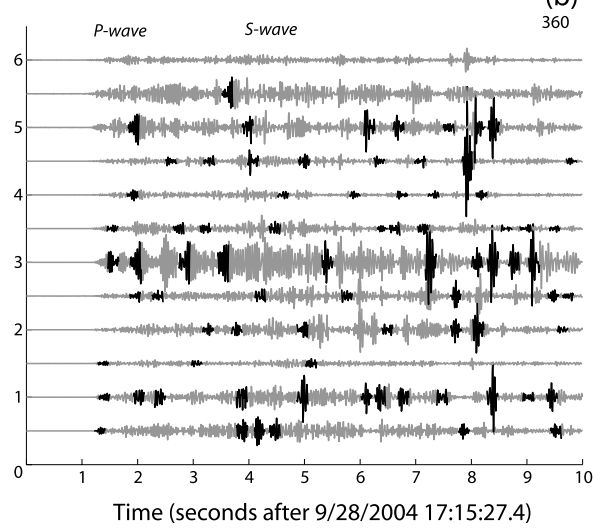

Figure 2. (a) Raw and (b) 20-Hz high-pass-filtered north-component acceleration seismograms recorded by the UPSAR during the first $10 \mathrm{~s}$ of the 2004 Parkfield earthquake. The station name is marked on the left. The high-frequency bursts picked by our automated algorithm with a signal-to-noise ratio of 50 are indicated in black in Figure $2 \mathrm{~b}$. Records are lined up with the origin time of the Parkfield mainshock as indicated. P- and S-wave arrivals are indicted on the figure for reference.

maximum dynamic stress in the seismic waves just prior to the arrival of each burst. For plane waves, the peak dynamic stress $\sigma_{d}$ is equal to $\nu \mathrm{G} / \beta$ [Hill and Prejean, 2007], where $G$ is the shear modulus, $\nu$ is the peak particle velocity, and $\beta$ is the shear-wave velocity. Values of $\nu$ were obtained by integrating the strong motion acceleration records. The triggering stress of a burst was defined as the maximum value of $\sigma_{d}$, on all three components, within a 1 second window prior to its arrival. Similar instantaneous triggering was observed during the passage of surface waves generated by the 2002 Denali earthquake [Prejean et al., 2004; Gomberg et al., 2008], and 2004 Sumatra earthquake [e.g., Miyazawa and Brodsky, 2008]. Repeating the calculations with longer time windows did not produce a significant change in the threshold.

[13] Figure 4 shows the distributions of triggering stresses for different SNR. Taking $G=0.3 \mathrm{GPa}$ and $\beta=$

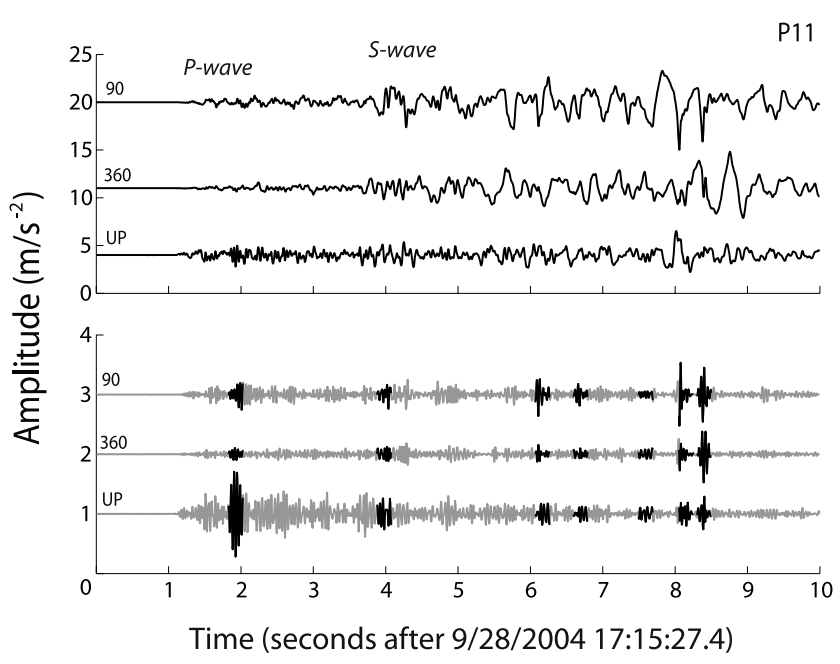

Figure 3. (top) Raw and (bottom) 20-Hz high-pass-filtered three-component seismograms recorded by station P11 during the first $10 \mathrm{~s}$ of the Parkfield mainshock. The high-frequency bursts picked by our automated algorithm with a signal-to-noise ratio of 50 are indicated in black.
$326 \mathrm{~m} / \mathrm{s}$ [Fletcher et al., 2006] for the shallow crust, gives a stress amplitude threshold of $0.02 \mathrm{MPa}$ for $\mathrm{SNR}=50$. We define the threshold as the stress level above which $95 \%$ of bursts are triggered. These stresses are consistent with the range of 0.03 to $0.05 \mathrm{MPa}$ obtained from the high-frequency triggering analysis of bursts observed during strong motion from the Chi-Chi earthquake [Fischer et al., 2008].

\section{Location and Size of the Bursts}

[14] In the Taiwan study [Fischer et al., 2008], observed a lack of correlation across a sub-array with average station spacing of $3 \mathrm{~km}$. The failure to identify a burst on more than one station implied they were within 750 meters of the

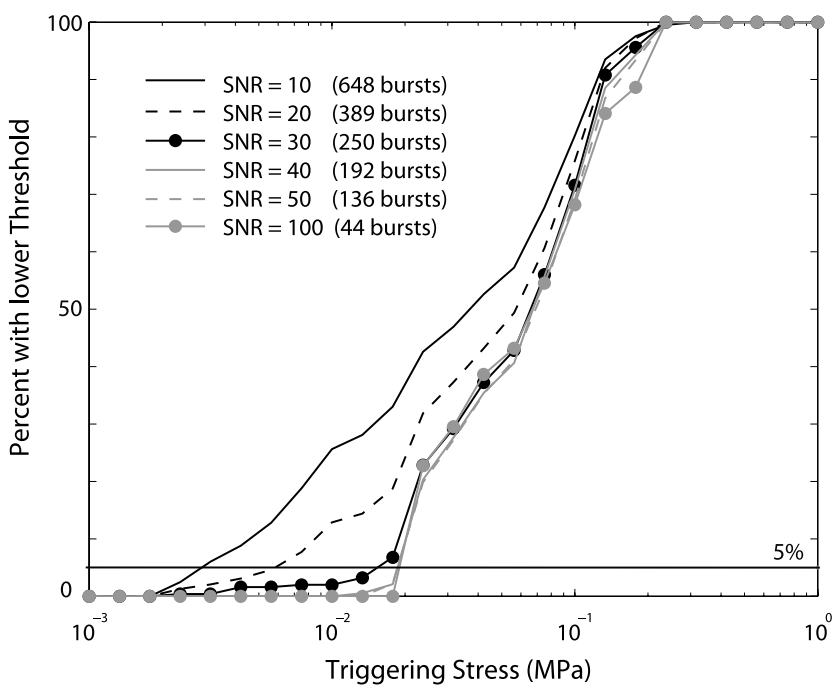

Figure 4. Triggering threshold for a range of signal-tonoise ratios (SNR). The horizontal line indicates the 95\% Threshold. The intersection of this line with the curves indicates the triggering stress. For our preferred $\mathrm{SNR}=50$, the threshold is $0.02 \mathrm{MPa}$. For SNR $>30$, triggering thresholds cluster about our preferred value of $0.02 \mathrm{MPa}$ at $\mathrm{SNR}=50$. 
station and that the magnitude had to be below $M w=0$. The nearest neighbors in the UPSAR array are 40 meters apart. Lack of correlated bursts at UPSAR implies that they are within 20 meters of a station and the magnitude of the largest amplitude burst has $M w=-1$ and corresponding seismic potency $P_{O}=1.2 \times 10^{-5} \mathrm{~km}^{2} \mathrm{~cm}$, where this magnitude was determined from the spectral amplitude in the low frequency limit. Because the spectrum is contaminated by energy from the Parkfield mainshock at low frequency, we assumed that the spectral amplitude at $10 \mathrm{~Hz}$ gives an adequate approximation to the magnitude. It is of interest to note that for vertically propagating SH-waves, peak dynamic stresses are found at the 1/4 wavelength depth [Sleep and Ma, 2008]. The dominant frequency from the average spectrum of all the records is about $2 \mathrm{~Hz}$.. The corresponding wavelength with the nearsurface $\mathrm{S}$-wave velocity $\beta=326 \mathrm{~m} / \mathrm{s}$ is about $140 \mathrm{~m}$, and the $1 / 4$ wavelength is about $35 \mathrm{~m}$. This value is close to the distance where we think the bursts are produced.

\section{Discussion}

[15] In this study we observed many high-frequency bursts during strong motion from the 2004 Parkfield earthquake and its immediate largest aftershocks recorded by the UPSAR array. After investigating and ruling out several possible artifacts associated with instruments (see Text S1), we hypothesize that these signals are generated by sources within $20 \mathrm{~m}$ of the receivers that were dynamically triggered by the strong ground motion. This hypothesis is supported by three lines of evidence. First, the high-frequency bursts were only observed during the strong shakings (Figure 4). Second, although an individual burst was recorded on all three components of a given station, it could not be identified at other nearby stations (Figures 2 and 3). This lack of correlation is most likely due to the relatively small amplitudes and high-frequencies of the bursts, and to the extremely high attenuation in the highly fractured and weathered uppermost crust. Third, the threshold stress required for triggering found here $(0.02 \mathrm{MPa})$ is consistent with a previous estimate for bursts triggered by 1999 ChiChi earthquake in Taiwan [Fischer et al., 2008].

[16] Recent studies using repeating earthquakes have found reduced seismic velocities in the top few hundred meters of the crust associated with strong motions from nearby large earthquakes [e.g., Rubinstein and Beroza, 2005; Peng and Ben-Zion, 2006]. The reductions are most likely caused by the opening of pre-existing cracks during dynamic shaking, and are typically followed by logarithmic recovery. We speculate that this cracking process is accompanied by frictional loss from discrete events that reradiate energy to higher frequencies, some of which are recorded as high-frequency bursts by nearby stations. Large, but very rare bursts have been identified in the Parkfield region [Sleep and Ma, 2008] and have implications for theoretical limits of ground motion. In contrast, the numerous small high-frequency events observed in our study may be ubiquitous and play an important role in the attenuation of strong motion in the shallow crust.

[17] Acknowledgments. We thank Joe Fletcher, Paul Spudich, and Larry Baker for making the waveforms of the UPSAR available. We thank Dominic Assimaki for pointing out the work of Bonilla et al. [2005]. This work has benefitted from helpful reviews by John Vidale, Paul Spudich, and Norm Sleep. This research was supported by the Southern California Earthquake Center. SCEC is funded by NSF Cooperative Agreement EAR-0106924 and USGS Cooperative Agreement 02HQAG0008. The SCEC contribution number for this paper is 1201 .

\section{References}

Aster, R. C., and P. M. Shearer (1991), High-frequency borehole seismograms recorded in the San Jacinto fault zone, southern California. Part 2. Attenuation and site effects, Bull. Seismol. Soc. Am., 81, $1081-1100$.

Blakeslee, S., and P. Malin (1991), High-frequency site effects at two Parkfield downhole and surface stations, Bull. Seismol. Soc. Am., 81, 332345 .

Bonilla, L. F., R. J. Archeleta, and D. Lavellee (2005), Hysteretic and dilatant behavior of cohesionless soils and their effects on nonlinear site response: Field data observations and modeling, Bull. Seismol. Soc. Am., 95, 2373-2395

Cranswick, E. (1988), The information content of high-frequency seismograms and the near-surface geologic structure of "hard rock" recording sites, Pure Appl. Geophys., 128, 333-363.

Chen, Y., C. G. Sammis, and T.-L. Teng (2006), A high frequency view of the 1999 Chi-Chi, Taiwan, source rupture and fault mechanics, Bull. Seismol. Soc. Am., 96, 807-820.

Ebel, J. E. (1989), The effect of crustal scattering on observed highfrequency earthquake seismograms, Geophys. J. Int., 98, 329-341.

Fischer, A. D., C. G. Sammis, Y. Chen, and T. L. Teng (2008), Dynamic triggering by strong motion $P$ - and $S$-waves: Evidence from the 1999 Chi-Chi, Taiwan earthquake, Bull. Seismol. Soc. Am., 98, 580-592.

Fletcher, J. P., P. Spudich, P. Goldstein, J. Sims, and M. Hellweg (1992), The USGS Parkfield, California dense seismograph array-UPSAR, Bull. Seismol. Soc. Am., 82, 1041-1070.

Fletcher, J. P., P. Spudich, and L. M. Baker (2006), Rupture propagation of the 2004 Parkfield, California, earthquake from observations at the UPSAR, Bull. Seismol. Soc. Am., 96, S129-S142, doi:10.1785/01200050812.

Frankel, A. D., D. L. Carver, and R. A. Williams (2002), Nonlinear and linear site response and basin effects in Seattle for the M6.8 Nisqually, Washington, earthquake, Bull. Seismol. Soc. Am., 92, 2090-2109.

Gomberg, J., J. L. Rubensteing, Z. Peng, K. C. Creager, J. E. Vidale, and P. Bodin (2008), Widespread triggering of nonvolcanic tremor in California, Science, 319, 173, doi:10.1126/science.1149164

Hanks, T. C. (1982), $f_{\max }$, Bull. Seismol. Soc. Am., 72, 1867-1880.

Hill, D. P., and S.G. Prejean (2007), Dynamic triggering, in Treatise on Geophysics, vol. 4, Earthquake Seismology, edited by H. Kanamori, pp. 257-292, Elsevier, Amsterdam.

Hill, D., et al. (1993), Seismicity remotely triggered by the magnitude 7.3 Landers, California, earthquake, Science, 260, 1617-1623.

Holzer, T. L., T. L. Youd, and T. C. Hanks (1989), Dynamics of liquefaction during 1987 Superstition Hills, California, earthquake, Science, 244, $56-59$.

Langbein, J., et al. (2005), Preliminary report on the 28 September 2004, M6.0 Parkfield, California earthquake, Seismol. Res. Lett., 76, 10-26.

Miyazawa, M., and E. E. Brodsky (2008), Deep low-frequency tremor that correlates with passing surface waves, J. Geophys. Res., 113, B01307, doi:10.1029/2006JB004890.

Obara, K. (2002), Nonvolcanic deep tremor associated with subduction in southwest Japan, Science, 296, 1681-1699.

Peng, Z., and Y. Ben-Zion (2006), Temporal changes of shallow seismic velocity around the Karadere-Duzce branch of the north Anatolian fault and strong ground motion, Pure Appl. Geophys., 163, 567-599.

Peng, Z., J. E. Vidale, and H. Houston (2006), Anomalous early aftershock decay rates of the 2004 M6 Parkfield earthquake, Geophys. Res. Lett., 33, L17307, doi:10.1029/2006GL026744.

Prejean, S. G., D. P. Hill, E. E. Brodsky, S. E. Hough, M. J. S. Johnston, S. D. Malone, D. H. Oppenheimer, A. M. Pitt, and K. B. RichardsDinger (2004), Remotely triggered seismicity on the United States west coast following the $M w 7.9$ Denali Fault earthquake: The 2002 Denali Fault earthquake sequence, Bull. Seismol. Soc. Am., 94, 348-359.

Rubinstein, J. L., and G. C. Beroza (2005), Depth constraints on nonlinear strong ground motion from the 2004 Parkfield earthquake, Geophys. Res. Lett., 32, L14313, doi:10.1029/2005GL023189.

Shearer, P. M., and J. A. Orcutt (1987), Surface and near-surface effects on seismic waves-theory and borehole seismometer results, Bull. Seismol. Soc. Am., 77, 1168-1196.

Sleep, N. H., and S. Ma (2008), Production of brief extreme ground acceleration pulses by nonlinear mechanisms in the shallow subsurface, Geochem. Geophys. Geosyst., 9, Q03008, doi:10.1029/2007GC001863.

Vernon, F. L., J. Fletcher, L. Carroll, A. Chave, and E. Sembrera (1981), Coherence of seismic body waves from local events as measured by a small-aperture array, J. Geophys. Res., 96, 11,981-11,996. 
Vernon, F. L., G. L. Pavlis, T. J. Owens, D. E. McNamara, and P. N. Anderson (1998), Near-surface scattering effects observed with a highfrequency phased array at Pinyon Flats, California, Bull. Seismol. Soc. Am., 88, 1548-1560.

Wilson, D. C., and G. L. Pavlis (2000), Near-surface site effects in crystalline bedrock: A comprehensive analysis of spectral amplitudes deter- mined from a dense, three-component seismic array, Earth Interact., 4. (Available at http://EarthInteractions.org)

A. D. Fischer and C. G. Sammis, Department of Earth Sciences, University of Southern California, Los Angeles, CA 90089-0740, USA. (adfische@usc.edu)

Z. Peng, School of Earth and Atmospheric Sciences, Georgia Institute of Technology, Atlanta, GA 30332, USA. 